\title{
Spatial Information in Support of 3D Flood Damage Assessment of Buildings at Micro Level: A Review
}

\author{
S. Amirebrahimi ${ }^{\text {a, }}$, A. Rajabifard ${ }^{\text {a }}$, S. Sabri ${ }^{\text {a }}$, P. Mendis ${ }^{\text {b }}$ \\ a Centre for SDIs and Land Administration, University of Melbourne, Australia - amis@unimelb.edu.au, abbas.r@unimelb.edu.au, \\ Soheil.sabri@unimelb.edu.au \\ ${ }^{\mathrm{b}}$ Advanced Protective Technologies for Engineering Structures (APTES) Group, University of Melbourne, \\ pamendis@unimelb.edu.au,dtngo@unimelb.edu.au
}

KEYWORDS: Flood Damage Assessment, Technology Review, BIM, GIS, Integration, Building, Resilience

\begin{abstract}
:
Floods, as the most common and costliest natural disaster around the globe, have adverse impacts on buildings which are considered as major contributors to the overall economic damage. With emphasis on risk management methods for reducing the risks to structures and people, estimating damage from potential flood events becomes an important task for identifying and implementing the optimal flood risk-reduction solutions. While traditional Flood Damage Assessment (FDA) methods focus on simple representation of buildings for large-scale damage assessment purposes, recent emphasis on buildings' flood resilience resulted in development of a sophisticated method that allows for a detailed and effective damage evaluation at the scale of building and its components. In pursuit of finding the suitable spatial information model to satisfy the needs of implementing such frameworks, this article explores the technical developments for an effective representation of buildings, floods and other required information within the built environment. The search begins with the Geospatial domain and investigates the state-of-the-art and relevant developments from data point of view in this area. It is further extended to other relevant disciplines in the Architecture, Engineering and Construction domain (AEC/FM) and finally, even some overlapping areas between these domains are considered and explored.
\end{abstract}

\section{INTRODUCTION}

Floods are the most common and costliest natural disaster around the world. It has been recognised that their effective management is possible only by employing comprehensive riskbased models to reduce both hazard and its consequences. This is in contrast to traditional methods that only try to contain the hazard itself (Birkmann et al., 2013). A major advantage of the former method lies in its holistic view towards risk and consideration for flood consequences as evidence for decision making. Accordingly, they employ Flood Damage Assessment (FDA) as their major component to identify the potential impacts of a flood in different scenarios of change, as well as further evidence for cost-benefit analysis of adopting alternative flood risk-reduction measures. FDA can generally be performed in three major scales; i.e. Micro, Meso and Macro (Merz et al., 2010). Amongst the numerous FDA models proposed, only Micro level methods can allow for high resolution object-based assessment of damage to individual elements at risk (Apel et al., 2009). This has implications in several application domains such as insurance, urban planning and management, and land administration.

Buildings have significant importance to the economy and the recent emphasis on the safety of people and the performancebased design of buildings against floods require evidence-based decision support to a range of decision makers to ensure the flood resilience of buildings (Van de Lindt \& Taggart, 2009). This calls for an effective assessment of the potential flood impacts for better understanding of buildings' behaviour against floods and identifying the potential areas of improvement or retrofitting (Messner et al., 2007). The current Micro-level FDA methods have limitations for taking into account the distinct behaviour of buildings against damaging effects of flood (Merz et al., 2010). The misrepresentation of FDA data inputs (e.g. buildings) in the majority of existing micro-level FDA models has resulted in a significant increase in the uncertainty of the simulation outcomes and consequently compromising their reliability (Apel et al., 2009; Amirebrahimi et al., 2015). Recently, Amirebrahimi et al. (2015) proposed and evaluated a detailed micro-level FDA framework that assesses potential flood damages by accounting for the unique behaviour of building against the spatiotemporal variation of flood parameters during a flood event. This dynamic simulation allows for identification of weak points in the building and not only highlights the mode and cost of potential floodwater damages to individual structural and non-structural components, but also provides a $3 \mathrm{D}$ visualisation of this information and the location of damaged components in the building. This framework requires various data from multiple sources to be integrated into a unified format for satisfying the information requirements of the framework. These information requirements are discussed in detail by Amirebrahimi et al. (2016) and include digital elevation model, building and utilities data, spatiotemporal flood information (e.g. depth and velocity), and cost of building components. Besides highlighting these themes and elements within each, they also emphasised that for an effective analysis of damage and taking into account the fluidstructure interactions that lead to building damages, it would be crucial to (a) use proper geometries to represent objects, (b) have the semantics of each object defined at the required levels, and finally (c) each object's relationships with other elements to

* Corresponding author 
be clearly specified and stored. Therefore, any data technology used as the basis of this FDA framework should include and implement these aspects.

This paper explores the state-of-the-art technical developments for satisfying the abovementioned information requirements and the established criteria towards creating a unified data foundation for the discussed Micro-level FDA framework. As Geographic Information Systems (GIS) play a crucial role in managing spatial information about buildings and the flood parameters for assessment and visualisation of damage, in Section 2, we first present the outcomes of our investigation regarding those important and relevant developments in the Geospatial domain. Next in Section 3, we further discuss those other relevant developments in the Architecture, Engineering and Construction/Facility Management (AEC/FM) domains. Later in Section 4, the overlap between these disciplines and potential integration between some of the technologies within them is discussed and summarised. Finally in Section 5, further discussion is provided, the conclusions of the paper are presented, and future research directions are highlighted.

\section{DEVELOPMENTS IN GEOSPATIAL DOMAIN}

The reliance of many of the analyses and decisions nowadays on the location of elements underpins the importance of the geospatial information and GIS systems. The digital representation and geometrisation of the physical world in GIS systems were traditionally projected in various ways on twodimensional digital maps by either Vector or Raster (O'Sullivan \& Unwin, 2003). Some examples of vector data formats include the ESRI ShapeFile, Mapinfo's TAB files, GeoJSON, etc. The Shapefile is the most common and widely accepted vector data format in the Geospatial domain and based on open specifications (Zlatanova et al., 2012). Shapefiles provide support for geometries (i.e. point, line and polygons), basic semantics, and simple textures. Since the release of ESRI ArcGIS 10, shapefiles can also model 3D geometries using polyhedron. However, no topology or relationships between objects are accounted for in this format. Also, the semantics are handled at the feature layers than objects themselves. The representation of the building using shapes along its attributes constitutes the common data inputs for current practice of FDA. Yet, it is ineffective for representing the complex building structure required for detail damage assessment.

ESRI Building Interior Space Data Model (BISDM) (ESRI, 2011) is a vector-based conceptual data model for 2D representation of a building, its floors and spaces. Although by using the floor-plan layout and the ceiling height information, the walls - as extruded lines - can be represented, this data model is limited to 2D representation of the building, its floors and ceiling and interior spaces, and other aspects of the building are not included. Raster, on the other hand, is a continuous representation of the real world entities using regular (or even irregular) grid cells called 'pixels'. In this format, each pixel can only have one value representing the characteristics of the entity/phenomenon at that location. The most common raster file formats include ESRI Grid file, JPEG, GeoTIFF, etc. The use of these formats for representation of buildings, depending on the raster pixel size, can be limited. In addition, although its adoption for the flood extent and depth is commonplace, representing multiple flood parameters like depth and velocity using one raster is not feasible and generally achieved through a combination of raster and vector. Interoperability is one of the major challenges in the Geospatial domain. Open Geospatial Consortium (OGC) as the responsible body for establishing interoperability uses standards or services like Web Map Service (WMS) and Web Feature Service (WFS) for this purpose (Peachavanish et al., 2006; Karimi \& Akinci, 2010). Geographic Markup Language (GML) by OGC (2007b) is the most comprehensive modelling language and an XML-based ISO standard for storing and exchanging geographic information and the underlying data structure for the aforementioned geographic services. Previously, GML could only support 2D vector-based geo-information. In its most recent version, GML 3, the $3 \mathrm{D}$ geometrical and temporal representation of features, raster data as well as topological relationships are also included. It, however, does not contain the semantics of geographic features which are crucial in understanding of the nature of the object and for use in various analyses. For instance, without semantics defined, it would be challenging to answer questions like "which object the water is contacting with?” Therefore as described by OGC (2007a), researchers and practitioners take advantage of GML's modular structure and design community-specific "application schemas" to define semantics for their particular domains. In here, a relevant example of GML application schema is the Water Modelling Language (WaterML) which is mainly structured according to GML's "coverage" concept and allows for storage of spatiotemporal hydrological information and observations.

Two-dimensional geospatial data are limited for describing and representing the complexity of the 3D world in urban context in support of essential analysis for multifaceted urban management processes (Duncan \& Abdul-Rahman, 2013). The review of the literature suggests a paradigm shift in the analysis and visualisation from the traditional 2D approaches into sophisticated 3D methods for a variety of applications in the complex urban environments (Kolbe, 2009). 3D GIS shares similarities with 2D GIS functions, but is mainly used for handling the more realistic and detailed 3D geo-information. From geometry point of view, the accepted 3D modelling techniques as the basis of most file formats in the Geospatial domain include the "Boundary Representation (B-Rep)" or "swept solid geometry" (Isikdag \& Zlatanova, 2009b). Zlatanova et al. (2012) also discussed the applications of "Voxel", a three-dimensional equivalent of raster format for representation of 3D continuous geographic features.

A variety of 3D data formats and standards have been developed by the standardisation organisations or particular vendors in the Geospatial domain. The majority of these data formats are goal-specific and their variation may be in terms of their presentation, usage and applications which they serve (Zlatanova et al., 2012; Duncan \& Abdul-Rahman, 2013). Nagel (2014) classifies the representation of the building in these information models into Geometric and Graphical building models (e.g. VRML, X3D, COLLADA, 3D PDF, KML), and urban information models (e.g. CityGML and IndoorGML).

VRML and its successor, X3D are the most widely used formats for exchange of graphics and 3D visualisation over the web. VRML requires large storage capacity and does not support XML. While X3D resolved these issues, neither provide semantics for objects; and the relationships and topology between them are not accounted for. Another quite recent development is the 3D PDF that allows for an interactive 3D 
visualisation of building designs. The semantics of 3D PDF lie in the name of the layer and they are normally very large in size.

COLLADA is an XML-based open standard and an exchange format for $3 \mathrm{D}$ information between diverse applications. It supports 3D geometry, topology, texture, effects, animation and also multi-representation of objects. Although a detailed representation of building is possible in COLLADA, it only accounts for very basic semantics of the objects. Furthermore, the explicit relationships, as well as the attributes for further description of objects are missing. KML (OGC, 2008) is an OGC standard that can be linked to COLLADA files for realistic visualisation purposes. KML is XML-based and with geometry definitions similar to GML. It is widely used for a variety of web applications to annotate and visualise geographic features. Although KML supports 3D geometries like B-Rep and extrusion, similar to previously discussed formats, its objects are presented using their geometries with very basic semantics.

The Virtual 3D City Model, as a subset of Urban Information Models (UIM), is an important concept in the Geospatial domain and aims to develop georeferenced virtual representation of urban data by means of 3D virtual environments (Stadler \& Kolbe, 2007). Different frameworks have been proposed for this purpose and the evidence in the literature suggests a growth in the number of 3D city models around the globe (Zhao et al., 2013). The initial focus of these models was on 3D visualisation and they bear no analytical capabilities (Groger \& Plumer, 2012). The visualisation is only one of the applications of these models. By utilising such rich urban data along with the querying and analysis capabilities in 3D GIS, the use of 3D city models can go beyond pure visualisation and can benefit a variety of urban management processes like noise modelling and propagation, urban planning, disaster management and emergency response, Utility network management, etc. In addition, studies like Schulte and Coors (2009), Mioc et al. (2011), Kemec et al. (2010) adopted 3D virtual city models for flood risk management. However, the sole purpose of these studies was on visualisation of flood extent and depth in an urban context and no structural elements or the interior aspects of the building and/or damage analysis had been included.

Duncan and Abdul-Rahman (2013), Gia et al. (2013) and Valencia et al. (2015) reviewed and summarised the existing 3D Virtual City Models as well as those spatial data models that have been used as the foundation of 3D city modelling. Some of the important models include the Simplicial Simplex Model (SSM), Urban Data Model (UDM), 3D TIN, ESRI 3D City Information Model, AriBIS, City Geographic Markup Language (CityGML) (OGC, 2012) and the INSPIRE data specification on buildings (INSPIRE, 2013).

The most prominent and comprehensive standard to represent the built environment in 3D within the Geospatial domain is the OGC's CityGML (El-Mekawy et al., 2011). CityGML is an application schema of the GML 3 and is XML-based. It is modularised and conceptually organises urban features in the "core" and 11 other thematic modules including terrain, transportation objects, water bodies, vegetation, land use information, buildings, city furniture and bridges. CityGML defines the semantics, geometry, topology, attributes as well as the appearance of these features and their relationships (Stadler
\& Kolbe, 2007). A central part of the CityGML is the 3D building model and much effort has been put for its modelling in this standard. Buildings in CityGML can be represented simultaneously in five different levels of details (LoDs). The LoD4 is the richest representation of a building and contains its external and internal features as well as its furniture.
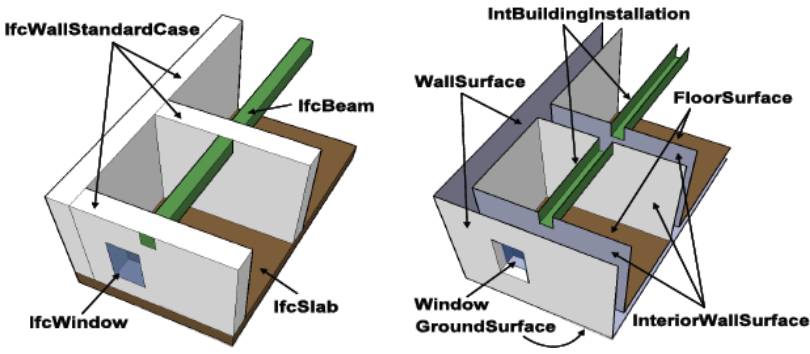

Figure 2: Building component representation in IFC [left] and surface representation in CityGML [right]

In CityGML many building components like foundation, columns, beams, slabs, connections and other structural aspects are not modelled or all are represented by generic objects like "building installations" without the details of each specialised component. In addition, the building components are modelled using surfaces instead of actual 3D objects. For example, as illustrated in Figure 2[right], the wall object in this standard is not explicitly defined and instead, is represented by "wall surface" and "interior wall surface" objects. This is the case of many other building elements like floors, ceilings and roofs. Therefore, many limitations in terms of assignment of material or confusion in use of the full geometry of any of these elements exist and accordingly, this CityGML cannot be easily employed for FDA purposes.

CityGML is not a universal 3D city model as it was not possible to include the requirements of many applications in its original development. However, its extensible structure allows for its extension for inclusion of those missing entities. Many different CityGML extensions, called Application Domain Extensions (ADEs), have been developed for a variety of use cases and applications. Some examples include the Indoor Spatial Data Model (Kim et al., 2013), Utility Network (UtilityNetworkADE) (Becker et al., 2010), Geotechnical objects and features (Tegtmeier et al., 2013), and Dutchspecific elements for their Spatial Data Infrastructure (SDI) in the IMGeo ADE (Van den Brink et al., 2012).

Water bodies in CityGML include another important aspect of this format. However, except for the surface representation of the boundaries of water bodies (e.g. water surface or the surface interfacing the water body to the ground), CityGML does not support the other flood characteristics like velocity. To represent the dynamism and spatiotemporal distribution of flood depths in CityGML, the HydroADE was developed by Schulte and Coors (2009). The main purpose of this extension was for $3 \mathrm{D}$ visualisation only and again, other important aspects of flood like velocity were overlooked.

Based on the detailed investigation in this study, it was realised that all these ADEs are highly specialised specific for particular domain/application; and in the absence of an FDA-specific $\mathrm{ADE}$ at the moment, none of the existing ADEs can fully accommodate the requirements of FDA discussed previously. 
IndoorGML (OGC, 2014) is another OGC standard developed to complement CityGML for storage and exchange of indoor spatial information about the building. It can model, store, and manage primal (volumetric and boundary representation) as well as dual (the hierarchical graph model and its connectivity) representation of the rooms with their semantic details. Although it appears as a new standard for modelling of the building interior, the representation of building elements and rooms in primal view of the IndoorGML is not much different from the CityGML and accordingly similar limitations is associated with it for use in FDA.

As described in the presented standards and developments in the Geospatial domain, flood depth and extent information can be represented in 2D and 3D. However, the other characteristics of flood like velocity or contamination are missing. Furthermore, most standards and formats cannot fully represent buildings and their components. A deeper investigation also showed that no single framework or information model can at the moment provide a complete set of building and flood information together in support for a detailed FDA on buildings. For these reasons, the direction of the investigation was shifted towards other disciplines like AEC/FM which will be discussed next.

\section{DEVELOPMENTS IN AEC/FM DOMAIN}

In contrast to the Geospatial field, other disciplines in the AEC/FM domain require more detailed design of the building and infrastructure models (as built or very close to it). Normally in this domain, buildings are modelled in the highest level of detail with detailed representation of their exterior and interior using high granularity and decomposition of objects (Van Berlo \& De Laat, 2010). Objects for this purpose can be based on complex mathematically-generated geometries such as Constructive Solid Geometry (CSG) that can potentially be used for building performance analysis and other building/facility management decisions (Isikdag \& Zlatanova, 2009b; Kensek \& Noble, 2014 pp 144).

2D CAD and Computer-Aided Modelling (CAM) for design and engineering purposes have long tradition in the AEC/FM domain. Due to the previously mentioned shift towards 3D information, although 2D versions of CAD tools can still be seen in the engineering practice, they have been mainly replaced by 3D CAD from various vendors like Autodesk. Also, similar to the Geospatial domain, interoperability is a challenge here, resulting in large costs within this industry. Accordingly, much effort is made in the AEC/FM domain to address that via standardising exchange formats. These efforts evolved from simple file and drawing exchange formats to those product- and domain-modelling initiatives that were followed by the objectoriented approaches to address the interoperability challenges (Isikdag et al., 2007a).

Drawing Exchange Format (DXF) and the Initial Graphics Exchange Specification (IGES) by Autodesk and a different joint initiative by Boeing and General Electric were amongst the initial developments. File size in DXF was small and the 2D graphic and geometry data could be efficiently exchanged. However, in this 2D format, semantics were limited and the topology of the objects was not accounted for. In addition, DXF, IGES, and the other similar exchange formats (e.g. DWG and DGN) are considered as fixed schemas, and accounting for the ever-expanding developments in various industries like piping, mechanical, electrical and other building systems in these formats would result in very large-size files and uninterpretable formats. Therefore, new initiatives emerged for domain-specific data exchange in the product model category which their overview has been provided by Tolman (1999) and Karimi and Akinci (2010). Some of these developments were later combined as part of a more comprehensive set of ISO standards. The more recent and important developments in this category include the CIMsteel Integration Standards (CIS/2), Green Building eXtensible Markup Language (gbXML), Building Construction eXtensible Markup Language (bcXML), Open Building Information eXchange, Automated Equipment Information eXchange (AEX), standard of the Associated General Contractors of America (agcXML), and BIM for Precast Concrete (BPC). It is further discussed that despite the success of these developments in their industry (e.g. CIS/2 in steel industry), they are very specific and their crossdisciplinary applications and interoperability were still an issue and to be addressed. In this way, only specific aspects of the building/facility are modelled resulting in its incomplete representation. This led to the development of a more comprehensive semantic Building Information Model exchange standards like Industry Foundation Classes (IFC). In the last decade, BIM has been the focus in the AEC/FM as a more efficient process for managing a building or facility. It further provides better interoperability and communication of all aspects of a building or facility information amongst the relevant participating organisations (Kensek \& Noble, 2014). $\mathrm{BIM}$ is an $\mathrm{N}$-dimensional digital representation of all aspects of a building and its components throughout its lifecycle along with their spatial and thematic properties in a single information repository. BIM has precise 3D geometry, it is semantically rich, and provides integrated information about building (Succar, 2009).

BuildingSmart is the largest regulatory body for BIM in $\mathrm{AEC} / \mathrm{FM}$ domain and developed the IFC as the standard for exchange of BIM data and relies on the STEP-based Express language to define building elements that represent various parts of a building, their material and geometry and other aspects in various domains including architecture, building Mechanical, Engineering and Plumbing (MEP) as well as Heating, Ventilation and Air Conditioning (HVAC) systems and services, structural systems, etc. IFC elements are structured in a hierarchical manner containing general baseclasses like geometry, topology, materials, actors, roles, costs and properties at highest levels; followed by those domain specific concepts like structural related elements at the lower levels. IFC supports a variety of geometries like points, vectors, parametric or conic curves, polygons as surfaces, swept solids, boundary representation, bounding boxes, and complex Constructive Solid Geometry (CSG). In addition, building elements are modelled as objects (in contrast to separate surfaces in CityGML) and their relationships are explicitly modelled (see Figure 2[left]). They establish semantic and additional properties for particular link between two or more building elements or products. Properties, on the other hand, describe a particular object in the IFC model and are mainly used in terms of an extensible set of attributes called "propertysets". Although it is the most comprehensive BIM exchange format, IFC may still lack various elements that would be addressed in the future versions. In the meantime however, according to the extensible structure of the IFC and its object- 
oriented design, its structure can be extended for different applications by defining new classes as sub-types to define new entities or extending the property-sets to include those required properties. Two examples of this extension are provided in Cemesova (2013) and Atazadeh et al. (2016) for building energy analysis and 3D cadastre applications.

While the main focus of the IFC is to model the building and its immediate surroundings, IFC4 includes additional geo-graphic elements that allows for representation of linear, point-, or areabased geographic features. Yet, it still seems to be inadequate to model complex geographically extended phenomena like floods.

An XML version of IFC standard, the ifcXML, has been derived from the Express model and targeted a larger range of tools, databases and users. IfcXML does not require the costly and complicated tools for implementation and querying of STEP-based IFC model. It further facilitates the transmission, querying and visualisation of BIM models over the Internet. Although it is more human-readable, yet ifcXML's large size is one of the major downsides of this format (Eastman et al., 2011 p.135). BimXML is an alternative to IFC and ifcXML and represents building information like site, building, floors, spaces and the building equipment using a simplified model (i.e. points, extruded shapes and spaces) for the BIM collaboration via web services. It is currently used worldwide (e.g. by Onuma System, Data Design System, Tokmo, and BIM Connect) and various plug-ins for BIM and CAD applications have been developed. BimXML is not a replacement for IFC and cannot manage the detailed building information the way IFC can.

A variety of building elements such as doors, windows, walls exist in a complex BIM model. For facilitating the identification and formal classification of the building elements, universal standard codes across the industry (e.g. UniClass, UniFormat, and OmniClass) have been developed. The most comprehensive development for all facets of AEC/FM domain throughout the entire lifecycle of the building and the built environment is the OmniClass (2013) which is designed to provide a shared terminology for classification, storage and retrieval of AEC/FM assembly information. In addition, UniFormat II (ASTM, 1993) with narrower focus, is a standard for building element classification. The classification codes can be used for exchanging product information; but are mainly for cost estimates and/or management of the building throughout its lifecycle. They provide a backbone for BIM models.

To summarise the developments in AEC/FM domain, similar to Geospatial domain, the two-dimensional information models in AEC/FM domain were found inadequate for effective representation of the complexity of buildings and the urban environment. Furthermore, the majority of the explored formats focus on the representation of industry-specific data and products and therefore, buildings could only be partially represented by these standards. BIM, as the most comprehensive development in AEC/FM, allows for managing building information throughout its lifecycle. Yet, the focus of BIM is mainly on buildings and although efforts have been made to include geographically extended entities in IFC4, the standard is still immature for representing complex geographically extended concepts like flood. BIM can facilitate the vulnerability and risk assessment (Guven et al., 2012) and by containing all the details of the building elements, it has been used for the evaluation of building damage from hazards like earthquake (e.g. Christodoulou et al., 2010; Georgiou \& Christodoulou, 2014). Despite the use of BIM for these applications, no use of this technology for FDA is yet considered and generally, it is suggested that BIM has been underutilised for risk and emergency management (Leite \& Akinci, 2012). This may be due to the inability of BIM to store or integrate the flood or similar large-scale information. These highlight the shortcoming of this standard/technology to perform/manage those tasks that are considered as the major strength in GIS.

\section{BIM-GIS INTEGRATION}

GIS and BIM originate from different domains and were developed for their specific needs. However, considering the strength of each, the integration of BIM and GIS can create a seamless and scale-independent view of the world across both domains that can benefit a variety of applications that meeting their requirements would not be possible by independent use of BIM or GIS. This is mainly due to the BIM and GIS disparities which are usually discussed in terms of their coordinate system, spatial scale, level of granularity and details in modelling of physical world, geometry representation method, Time scale, storage and access methods as well as the semantic mismatches between them (Van Oosterom \& Stoter, 2006; Isikdag \& Zlatanova, 2009b; El-Mekawy \& Ostman, 2010; Hijazi et al., 2010; Karimi \& Akinci, 2010). However, Van Berlo and De Laat (2010), Isikdag and Zlatanova (2009a) highlighted the benefits of the BIM-GIS integration and opportunities that makes it worthwhile for different applications like emergency response, construction management, etc. Furthermore, Isikdag and Zlatanova (2009a) and Dakhil and Alshawi (2014) discussed the potential use of BIM-GIS integration for damage assessment for different hazards like flood. For example, the semantic information of BIM and the spatiotemporal distribution of hazard parameters like flood depth and velocity can be combined and used in geo-analysis in a GIS environment for answering questions such as which parts of the electrical wiring have suffered damage from a particular simulated flood event or which wall linings should be replaced. From the previous research (e.g. Isikdag et al., 2008; Fosu et al., 2015) as well as the review of various attempts for integration of the BIM and GIS it can be perceived that they generally can be classified into three levels: i.e. application, process, and data levels. The sub-level methods as well as some examples of each are presented in Table 1. 
Table 1: Summary of BIM-GIS Integration methods

\begin{tabular}{|c|c|c|}
\hline Level & Sub-level & Sample literature \\
\hline \multirow[t]{2}{*}{ Application } & $\begin{array}{l}\text { Reconfiguring or rebuilding - where an existing GIS or BIM } \\
\text { tool is either modified by software patches or is rebuilt from } \\
\text { scratch to support the functions (or data formats) of the other. }\end{array}$ & Karimi and Akinci (2010). \\
\hline & $\begin{array}{l}\text { Linking- facilitates data transfer between BIM and GIS } \\
\text { software via use of API. }\end{array}$ & ArcSDE (ESRI, 2015) \\
\hline Process & N/A & $\begin{array}{l}\text { OWS-4 project by OGC (2007c), Park et al. (2014), Karan and } \\
\text { Irizarry (2015), Wu et al. (2014), Peachavanish et al. (2006) and } \\
\text { Akinci et al. (2010). }\end{array}$ \\
\hline \multirow[t]{4}{*}{ Data } & $\begin{array}{l}\text { One-way conversion between BIM and GIS (referred to } \\
\text { translation/conversion method) }\end{array}$ & $\begin{array}{l}\text { ArcToolbox Conversion Tools (ESRI, 2006), Wu and Hsieh } \\
\text { (2007), Herrlich et al. (2010), FME (Safe, 2013), BIMServer } \\
\text { (2015), IFCExplorer (FZK, 2012), Lee et al. (2009), Nagel et al. } \\
\text { (2009), Isikdag and Zlatanova (2009b), Donkers (2013), Isikdag } \\
\text { et al. (2007b), El-dabiry and Osman (2010). }\end{array}$ \\
\hline & $\begin{array}{l}\text { Extending standards on either BIM or GIS side to allow for } \\
\text { storage of data from the other domain (called Extension } \\
\text { method); or application schemas for an existing standard. }\end{array}$ & $\begin{array}{l}\text { Van Berlo and De Laat (2010), Cheng et al. (2013), IFG Project } \\
\text { (IAI, 2005), Mignard et al. (2011), Amirebrahimi et al. (2016) }\end{array}$ \\
\hline & $\begin{array}{l}\text { Two-way communication between the two models using an } \\
\text { intermediate tool or model (called Mediation). }\end{array}$ & $\begin{array}{l}\text { NIBU (Hijazi et al., 2010), Unified Building Model (El-Mekawy } \\
\text { et al., 2011), QUASY (Benner et al., 2005), Deng et al. (2016). }\end{array}$ \\
\hline & At DBMS level & $\begin{array}{l}\text { Pu and Zlatanova (2006), ProjectWise initiative (Bentley, 1998), } \\
\text { Li and He (2008), Van Oosterom and Stoter (2006). }\end{array}$ \\
\hline
\end{tabular}

At data level, the BIM-GIS integration is performed by unifying/combining BIM and GIS data or conversion of one type to another for use in the other or both domains. At process level however, methods intend to participate these platforms in tasks that require the capabilities of both, while they remain simultaneously distinct and live in the operation level. Application level integration methods modifies an existing BIM or GIS tool to be able to work with data formats of the other domain. In summary, while costly restructuring of the software packages in the application-level integration methods and underlying data integration in the process-level methods was highlighted as the main challenges in this section, Mignard and Nicolle (2014) discussed that nearly all the discussed proposals for integrating IFC and CityGML at data level led to similar problems which include little/partial semantic information about the building, data loss (semantics and/or geometry) in the transformation process, and lack of management of building and geographical elements in a single model. In addition, the simultaneous semantic mapping and geometry conversion is rarely tackled completely (Cheng et al., 2015). and without considering the context/application. Amirebrahimi et al. (2016) proposed a new BIM-GIS integration solution and developed an intermediate information model. This model was tested in an FDA scenario in Australia and according to a systematic evaluation, it was found to be effective to support resilient construction of buildings as well as improving the planning processes in local governments for reviewing risks to new developments in flood-prone areas. However, this data model is still to be improved since it only accounts for requirements of FDA for one residential building type and its damages against riverine flood. In this way, other building types and flood categories (e.g. coastal or flash floods) were not accounted for. In this way, although big steps have been taken towards overall integration of BIM and GIS for FDA purpose, due to the discussed shortcomings, none of the existing methods can at the moment provide support for use in FDA that considers any flood or building types.

\section{DISCUSSION AND CONCLUSIONS}

This article provided an extensive review of different technological developments in the Geospatial and AEC/FM domains from data structure point of view and evaluated their potential application for supporting a recently proposed microlevel FDA of buildings. A review of recent literature highlighted that the formats in the Geospatial domain have limited support for semantics of buildings and its complete geometric and semantic representation seem more suitable for outdoor and large-scale applications and visualisation purposes. In addition, 3D city models and CityGML also seem to be insufficient for the purpose of micro-level FDA. In contrast, BIM supports for a full representation of the building but has limitations in storing geographically extended phenomena like flood. It was further discussed that due to the requirements of micro-level FDA framework for capabilities of both BIM and GIS, the integration of these technologies offer more benefits and opportunities.

Accordingly, developing a BIM-GIS intermediate information model of a building type for an FDA scenario in Australian context highlighted the important role of this integration in resilient building construction and development assessment process. This is significant since the current statutory framework in Australia, similar to many other highly urbanised countries in Europe, UK and US, needs such a robust solution to speed up a quality decision making. The integration of BIMGIS is also predicted on a shift from 2D and paper-based 
evaluation of building proposals to the use of virtual geographic environment for simulating and understanding the accurate and detail aspects of flood damages. However, this integration has not been completely realised and the majority of the attempts are application-specific and not suitable for other applications with dissimilar requirements. For instance, while recent works partially could successfully integrate detailed building information with limited flood parameters, it seems there still exists a research gap for extending this method for other building types and flood categories. Hence, further research should look into and investigate the mechanisms that buildings and their components can be damaged from floods and extract the data requirements of a comprehensive FDA for buildings. By laying such knowledge foundation, a data foundation can be established. Subsequent future research will also need to consider the implications of BIM-GIS integration in assessing other extreme events such as hurricane and bush-fire hazards within resilient construction and urban planning frameworks. As such, a holistic data foundation is crucial for developing planning and decision support tools that facilitate societal efforts for creating a more disaster-resilient society in the future and towards meeting the objectives discussed in the post-2015 sustainable development goals.

\section{REFERENCES}

Akinci, B., Karimi, H. A., Pradhan, A., Wu, C.-C., \& Fichtl, G. (2010). CAD and GIS Interoperability through Semantic Web Services. In H. A. Karimi \& B. Akinci (Eds.), CAD and GIS Integration (pp. 199-222): Taylor and Francis (CRC Press).

Amirebrahimi, S., Rajabifard, A., Mendis, P., \& Ngo, T. (2015). A framework for a micro-scale flood damage assessment and visualization for a building using BIM-GIS integration. International Journal of Digital Earth. doi: 10.1080/17538947.2015.1034201

Amirebrahimi, S., Rajabifard, A., Mendis, P., \& Ngo, T. (2016). A BIM-GIS Integration Method in Support of the Assessment and 3D Visualisation of Flood Damage to a Building. Journal of Spatial Science, 1-34. doi: 10.1080/14498596.2016.1189365

Apel, H., Aronica, G. T., Kreibich, H., \& Thieken, A. H. (2009). Flood risk analyses-how detailed do we need to be? Journal of Natural Hazards, 49, 79-98.

ASTM. (1993). UniFormat II Standard. Retrieved 20 February 2015, from http://uniformat.com/

Atazadeh, B., Kalantari, M., Rajabifard, A., Ho, S., \& Ngo, T. (2016). Building Information Modelling for High-rise Land Administration. Transactions in GIS. doi: 10.1111/tgis.12199

Becker, T., Nagel, C., \& Kolbe, T. H. (2010). CityGML UtilityNetworkADE. Retrieved 25 March 2015, http://www.citygmlwiki.org/index.php/CityGML_Util ityNetworkADE

Benner, J., geiger, A., \& Leinemann, K. (2005). Flexible Generation of Semantic 3D Building Models. Paper presented at the 1st International Workshop on Next Generation 3D City models, Bonn, Germany.

Bentley. (1998). ProjectWise Initiative. Retrieved 5 July 2012, from http://www.bentley.com/enUS/Products/ProjectWise+Integration+Server/

BIMServer. (2015). BiMserver: Open source Building Information Modelserver. Retrieved 10 February 2015, from http://bimserver.org/
Birkmann, J., Cardona, O. D., Carreno, M. L., Barbat, A. H., Pelling, M., Schneiderbuer, S., . . . Welle, T. (2013). Framing Vulnerability, Risk and Societal Response: The MOVE Framework. Journal of Natural Hazards, 67, 193-211.

Cemesova, A. (2013). Enhancing BIM-based Data Transfer to Support the Design of Low Energy Buildings. (PhD Thesis), Cardiff University, Cardiff, Wales, UK.

Cheng, C. P., Deng, Y., \& Anumba, C. (2015). Mapping BIM Schema and 3D GIS Schema Semi-Automatically Utilizing Linguistic and Text Mining Techniques. Journal of Information Technology in Construction, 20, 193-212.

Cheng, J., Deng, Y., \& Du, Q. (2013, 30-31 October 2013). Mapping Between BIM Models and 3D GIS City Models of Different Levels of Details. Paper presented at the Proceedings of the 13th International Conference on Construction Applications of Virtual Reality, London, UK.

Christodoulou, S. E., Vamvatsikos, D., \& Georgiou, C. (2010, 14-16 September 2010). A BIM-Based Framework for Forecasting and Visualizing Seismic Damage, Cost and Time to Repair. Paper presented at the 8th European Conference on Product and Process Modelling (ECCPM), Cork, Ireland.

Dakhil, A., \& Alshawi, M. (2014, 8-10 September 2014). Client's Role in Building Disaster Management through Building Information Modelling. Paper presented at the 4th International Conference on Building Resilience, Salford Quays, United kingdom.

Deng, Y., Cheng, C. P., \& Anumba, C. (2016). Mapping between BIM and 3D GIS in different levels of detail using schema mediation and instance comparison. Automation in Construction, 67(2016), 1-21.

Donkers, S. (2013). Automatic Generation of CityGML LoD3 Building Models from IFC Models. (Masters of Geomatics), TU Delft, Delft, Netherlands.

Duncan, E. E., \& Abdul-Rahman, A. (2013, 27 - 29 November 2013). Urbanisation and 3D Spatial Modelling - A Geometric Approach. Paper presented at the ISPRS 8th 3D GeoInfo Conference \& WG II/2 Workshop, Istanbul, Turkey.

Eastman, C., Teicholz, P., Sacks, R., \& Liston, K. (2011). BIM Handbook: A guide to building information modeling fo owners, managers, designers, engineers and contractors (Second Edition) (Second ed.). New Jersey, NY: Wiley.

El-dabiry, T., \& Osman, H. (2010). Ontologies for Linking CAD/GIS. In H. A. Karimi \& B. Akinci (Eds.), $C A D$ and GIS Integration (pp. 171-198): Taylor and Francis (CRC Press).

El-Mekawy, M., \& Ostman, A. (2010, 12-14 June). Semantic Mapping: An Ontology Engineering Method for Integrating Building Models in IFC and CityGML. Paper presented at the 3rd ISDE Digital Earth Summit, Nessebar, Bulgaria.

El-Mekawy, M., Ostman, A., \& Shahzad, K. (2011). Towards Interoperating CityGML and IFC Building Models: A Unified Model Based Approach. In T. H. Kolbe (Ed.), Advances in 3D Geo-Information Sciences, Lecture Notes in Geoinformation and Cartography (pp. 7393). Berlin: Springer-Verlag.

ESRI. (2006). ArcToolbox Conversion Tools. Retrieved 30 June 2012, from 
http://webhelp.esri.com/arcgisdesktop/9.2/index.cfm? TopicName=ArcToolbox_window_basics

ESRI. (2011). ESRI Building Interior Space Data Model (BISDM). $\quad$ Retrieved 20 March 2015, from http://support.esri.com/en/knowledgebase/techarticles /detail/40585

ESRI. (2015). ArcSDE. Retrieved 20 March 2015, from www.esri.com/software/arcgis/arcsde

Fosu, R., Suprabhas, K., Rathore, Z., \& Clark, C. (2015, 27-29 October 2015). Integration of Building Information Modeling (BIM) and Geographic Information Systems (GIS) - a literature review and future needs. Paper presented at the Proceedings of the 32nd CIB W78 Conference, Eindhoven, The Netherlands.

FZK. (2012). IFC Explorer - an IFC to CityGML Converter. Retrieved 29 June 2012), from http://www.ifcwiki.org/index.php/IFCExplorer_CityG ML_-_IFC_Converter

Georgiou, C., \& Christodoulou, S. E. (2014). BIM-based Damage Assessment and Scheduling for PostEarthquake Building Rehabilitation. Paper presented at the 10th European Conference on Product and Process Modelling, Vienna, Austria.

Gia, T. A. N., Tran, P. V., \& Khac, D. H. (2013). Overview of Three and Four-Dimensional GIS Data Models. In J. J. Park (Ed.), Lecture Notes in Electrical Engineering, (Vol. 240, pp. 1013-1020). United States: Springer.

Groger, G., \& Plumer, L. (2012). CityGML - Interoperable Semantic 3D City Models. ISPRS Journal of Photogrammetry and Remote Sensing, 71(2012), 1233.

Guven, G., Ergen, E., Erberik, M. A., Kurc, O., \& Birgonul, M. T. (2012). Providing guidance for evacuation during emergency based on a real-time damage and vulnerability assessment of facilities. Paper presented at the 2012 ASCE International Conference on Computing in Civil Engineering Clearwater Beach, Florida.

Herrlich, M., Holle, H., \& Malaka, R. (2010). Integration of CityGML and Collada for High-Quality Geographic Data Visualization on the PC and Xbox 360. Berlin: Springer.

Hijazi, I., Ehlers, M., \& Zlatanova, S. (2010). BIM for GeoAnalysis (BIM4GEOA): Set Up of 3D Information System With Open Source Sofrware and Open Specification (OS). Paper presented at the 5th International 3D GeoInfo Conference, Berlin, Germany.

IAI. (2005). IFC for GIS (IFG). Retrieved 28 June 2012, from http://www.iai.no/ifg/Content/ifg_use_cases.htm

INSPIRE. (2013). INSPIRE Infrastructure for Spatial Information in Europe Data Specification on Buildings (version 3.0) - Technical Guidelines: European Commission.

Isikdag, U., Aouad, G., Underwood, J., \& Wu, S. (2007a). Building Information Models: A review on storage and exchange mechanisms. Paper presented at the CIB W78, Maribor, Slovenia.

Isikdag, U., Underwood, J., Aouad, G., \& Trodd, N. (2007b). Investigating the Role of Building Information Models as Part of an Integrated Data Layer: A Fire Response Management Case. Journal of Architectural Engineering and Design Management, 3, 124-142.

Isikdag, U., Underwood, J., aouad, G., \& Trodd, N. (2008). An investigation into the applicability of building information models in geospatial environment in support of site selection and fire response management processes. Advanced Engineering Informatics, 22(4), 504-519.

Isikdag, U., \& Zlatanova, S. (2009a, 24-26 June). A SWOT analysis on the implementation of Building Information Models within the Geospatial Environment. Paper presented at the proceedings of the Urban Data Management Society symposium 2009, Ljubljana, Slovenia.

Isikdag, U., \& Zlatanova, S. (2009b). Towards Defining a Framework for Automatic Generation of Buildings in CityGML Using Building Information Models. In J. Lee \& S. Zlatanova (Eds.), 3D Geo-Information Sciences: Lecture Notes in Geoinformation and Cartography, 2009, Part II (pp. 79-96): Springer Berlin Heidelberg.

Karan, E. P., \& Irizarry, J. (2015). Extending BIM Interoperability to Preconstruction Operations Using Geospatial Analyses and Semantic Web Services. Automation in Construction, 53, 1-12. doi: http://dx.doi.org/10.1016/j.autcon.2015.02.012

Karimi, H. A., \& Akinci, B. (2010). CAD and GIS Integration (1st ed.): Taylor and Francis Group (CRC Press).

Kemec, S., Duzgun, H. S., Zlatanova, S., Dilmen, D. I., \& Yalciner, A. C. (2010, 15-20 June 2010). Selecting 3D Urban Visualization Models for Disaster Management: Fethiye Tsunami Inundation Case. Paper presented at the 3rd International Conference on Cartography and GIS, Nessebar, Bulgaria.

Kensek, K. M., \& Noble, D. E. (2014). Building Information Modelling: BIM in Current and Future Practice. United States: Wiley and Sons.

Kim, Y., Kang, H. Y., \& Lee, J. (2013). Development of Indoor Spatial Data Model Using CityGML ADE. Paper presented at the ISPRS 8th 3DGeoInfo Conference \& WG II/2 Workshop, Istanbul, Turkey.

Kolbe, T. H. (2009). Representing and Exchanging 3D City Models with CityGML Lecture Notes in Geoinformation and Cartography (pp. 15-31): Springer.

Lee, G.-G., Kim, B.-s., Ka, K.-H., Kim, H.-k., Yoon, J.-Y., Kim, J.-J., \& Kim, W.-Y. (2009). Prototype Development of a Spatial Information Management System for Large-Scale Buildings. International Journal of Signal Processing and Pattern, 2(1), 1726.

Leite, F., \& Akinci, B. (2012). A Formalized Representation for Supporting Automated Identification of Critical Assets in Facilities during Emergencies Triggered by Failures in Building Systems. Journal of Computing in Civil Engineering.

Li, Y., \& He, Z. (2008). 3D Indoor Navigation: a Framework of Combining BIM with $3 D$ GIS. Paper presented at the 44th ISOCARP Congress 2008, Dalian, China.

Merz, B., Kreibich, H., Schwarz, J., \& Thieken, A. (2010). Review Article: "Assessment of Economic Flood Damage". Natural Hazards And Earth System Sciences, 10, 1697-1724.

Messner, F., Penning-Rowsell, E., Green, C., Meyer, V., Tunstall, S., \& Van der Veen, A. (2007). Evaluating flood damages: guidance and recommendations on principles and methods Integrated Flood Risk Analysis and Management Methodologies. Wallingford, UK. 
Mignard, C., Gesquiere, G., \& Nicolle, C. (2011, 20-25 November). SIGA3D: A Semantic BIM Extension to Represent Urban Environment. Paper presented at the The 5th International Conference on Advances in Semantic Processing, Lisbon, Portugal.

Mignard, C., \& Nicolle, C. (2014). Merging BIM and GIS using ontologies application to urban facility management in ACTIVe3D. Computers in Industry, 65(9), 12761290.

Mioc, D., Anton, F., Nickerson, B., Santos, M., Adda, P., Tienaah, T., . . . Tang, P. (2011). Flood Progression Modelling and Impact Analysis. In C. Jao (Ed.), Efficient Decision Support Systems - Practice and Challenges in Multidisciplinary Domains (pp. 227246). Published Online: InTech.

Nagel, C., Stadler, A., \& Kolbe, T. H. (2009, 27-31 July). Conceptual Requirements for the Automatic Reconstruction of Building Information Models from Uninterpreted 3D Models. Paper presented at the GeoWeb 2009 Academic Track - Cityscapes, Vancouver, BC, Canada.

O'Sullivan, D., \& Unwin, D. (2003). Geographic Information Analysis. New Jersey, U.S.: Wiley and Sons.

OGC. (2007a). Geography Markup Language. Retrieved 15 Februray 2015, from http://www.opengeospatial.org/standards/gml

OGC. (2007b). Geography Markup Language (GML) Encoding Standard (Vol. 3.2.1). Published Online: Open Geospatial Consortium Inc.

OGC. (2007c). OGC Web Services Architecture for CAD GIS and BIM. In P. Cote (Ed.): OGC.

OGC. (2008). Keyhole Markup Language (KML) standard: Open Geospatial Consortium.

OGC. (2012). OGC City Geography Markup Language (CityGML) Encoding Standard (Version 2.0). Published Online: Open Geospatial Consortium.

OGC. (2014). IndoorGML standard: Open Geospatial Consortium.

OmniClass. (2013). OmniClass Construction Classification System. Retrieved 13 July 2013, from http://www.omniclass.org/

Park, T., Kang, T., Lee, Y., \& Seo, K. (2014, 23-25 June 2014). Project Cost Estimation of National Road in Preliminary Feasibility Stage Using BIM/GIS Platform. Paper presented at the 2014 International Conference on Computing in Civil and Building Engineering, Orlando, Florida, United States.

Peachavanish, R., Karimi, H. A., Akinci, B., \& Boukamp, F. (2006). An ontological engineering approach for integrating CAD and GIS in support of infrastructure management. Advanced Engineering Informatics, 20, 71-88.

Pu, S., \& Zlatanova, S. (2006). Integration of GIS and CAD at DBMS level. Paper presented at the UDMS '06 25th Urban Data Management Symposium, Delft, Netherlands.

Safe. (2013). FME Software. Retrieved 29 August 2013, from http://www.safe.com/fme/fme-technology/

Schulte, C., \& Coors, V. (2009). Development of a CityGML $A D E$ for Dynamic 3D Flood Information. (Master of Science), University of Applied Sciences Stuttgart, Stuttgart, Germany. Retrieved from http://www.appliedgeoinformatics.org/index.php/agse/conference2009/pa per/viewFile/6/26
Stadler, A., \& Kolbe, T. H. (2007, 13 - 15 June 2007). SpatioSemantic Coherence in the Integration of 3D City Models. Paper presented at the 5th International ISPRS Symposium on Spatial Data Quality ISSDQ, Enschede, Netherlands.

Succar, B. (2009). Building information modelling framework: A research and delivery foundation for industry stakeholders. Automation in Construction, 18, 357375.

Tegtmeier, W., Zlatanova, S., van Oosterom, P. J. M., \& Hack, H. R. G. K. (2013). 3D-GEM: Geo-technical extension towards an integrated 3D information model for infrastructural development. Computers \& Geosciences. doi: doi.org/10.1016/j.cageo.2013.11.003

Tolman, F. (1999). Product Modelling Standards for the Building and Construction Industry: Past, Present and Future. Automation in Construction, 8(3), 227-235.

Valencia, J., Muñoz-Nieto, A., \& Rodriguez-Gonzalvez, P. (2015, 25-27 February 2015). Virtual Modelling for Cities of the Future. State-of-the-Art and Future Challenges. Paper presented at the 3D Virtual Reconstruction and Visualization of Complex Architectures, Avila, Spain.

Van Berlo, L., \& De Laat, R. (2010). Integration of BIM and GIS: The Development of the CityGML GeoBIM Extension. Paper presented at the 5th International 3D GeoInfo Conference, Berlin, Germany.

Van de Lindt, J. W., \& Taggart, M. (2009). Fragility Analysis Methodology for Performance-Based Analysis of Wood-Frame Buildings for Flood. Natural Hazards Review, 10, 113-123.

Van den Brink, L., Stoter, J. E., \& Zlatanova, S. (2012, 16-17 May 2012). Modelling an Application Domain Extension of CityGML in UML Paper presented at the 7th International Conference on 3D Geoinformation, Quebec, Canada.

Van Oosterom, P., \& Stoter, J. E. (2006). Bridging the Worlds of CAD and GIS. In S. Zlatanova \& D. Prosperi (Eds.), Large-Scale 3D Data Integration: Challenges and Opportunities (pp. 9-36). Boca Raton, FL: CRC Press, Taylor \& Francis Group.

Wu, I. C., \& Hsieh, S. H. (2007). Transformation From IFC Data Model to GML Data Model: Methodology and Tool Development Journal of Chinese Institute of Engineers, 30(6), 1085-1090.

Wu, W., Yang, X., \& Fan, Q. (2014). GIS-BIM Based Virtual Facility Energy Assessment (VFEA) - Framework Development and Use Case of California State University, Fresno. Paper presented at the Computing in Civil and Building Engineering 2014, Orlando, Florida, United States.

Zhao, J., Stoter, J., \& Ledouz, H. (2013). A Framework for the Automatic Geometric Repair of CityGML Models. Cartography from Pole to Pole: Lecture Notes in Geoinformation and Cartography, 2014, 187-202.

Zlatanova, S., Stoter, J. E., \& Isikdag, U. (2012, June 2012). Standards for Exchange and Storage of $3 D$ Information: Challenges and Opportunities for Emergency Response. Proceedings of the 4th International Conference on Cartography \& GIS, Albena. 